Summary

Anatolii Petrenko. Conventional Regulation of International Cooperation within OECD.

A characteristic trend in the development of international law in the second half of the XX century and early XXI century is the significant expansion of the law-making function of international intergovernmental organizations, which are obtaining an increasingly important role each year in resolving common issues in the political, economic, social, educational and other spheres, acting on behalf and in the interests of the states that formed them. In the system of international organizations of economic nature, an important place belongs to the Organization for Economic Cooperation and Development, which unites 36 industrialized countries as at 2020. During almost 70 years of the OECD existence, the organization has developed and adopted a wide variety of legal instruments aimed at addressing the widest range of issues related to various sectors of the economy, the fight against corruption, education and science, the environment, etc., recommendations, declarations, international agreements, ad hoc instruments. Based on a purely quantitative indicator, legally binding international treaties have a relatively small percentage of the entire normative body of acts adopted under the OECD. In total, 13 conventions were adopted within its framework, 10 of which are in force today. However, the conventions, developed under the aegis of the OECD, are quite successful examples of codification and progressive development of international law in the fields of: anti-corruption (Convention to Combat Bribery of Foreign Officials in International Business Transactions of December 17, 1997); administrative assistance in the field of taxation (Convention on Mutual Administrative Assistance in Tax Matters of January 25, 1988 and Protocol amending the Convention on Mutual Administrative Assistance in Tax Matters of May 27, 2010); counteraction to the tax base erosion and profit shift (Multilateral Convention to Implement Tax Treaty Related Measures to Prevent Base Erosion and Profit Shifting of November 24, 2016); nuclear safety, liability for damage caused by nuclear incidents (Convention on the Establishment of a Security Control in the Field of Nuclear Energy of December 20, 1957, Convention on Third Party Liability in the Field of Nuclear Energy of July 29, 1960 (Paris Convention, 1960), Convention of 31 January 1963 Supplementary to the Paris Convention of July 29, 1960 (Brussels Supplementary Convention).

Key words: Organization for Economic Cooperation and Development (OECD), law-making function of OECD, codification and progressive development of international law, Convention on Mutual Administrative Assistance in Tax Matters of 1988, convention to Combat Bribery of Foreign Officials in International Business Transactions of 1997.

DOI: 10.36695/2219-5521.2.2020.94

УДК 341

\title{
А. ПОЛАДОВ
}

Араз Поладов, докторант Бакинского государственного университета*

\section{ПРАВИЛА ЗАЩИТЫ ПЕРСОНАЛЬНЫХ ДАННЫХ В ПРАВОВОЙ СИСТЕМЕ США}

Постановка проблемы и ее актуальность. В формировании и развитии права на неприкосновенность частной жизни в Соединенных Штатах Америки в современном понимании решающую роль сыграл доктринальный поход, в частности, знаменитая статья «Право на личную жизни», опубликованная 15 декабря 1890 г. в «Гарвардском юридическом обозрении» С.Д. Уоррена и Л. Брандейса. С точки зрения неприкосновенности частной жизни статья определила направление развития законодательства США. Более того, это был главный прогрессивный шаг для дальнейшего развития этого права как в странах Англосаксонской, так и в странах Континентальной правовой системы. Хотя в статье указывается, что это право уже существовало во Франции и соответственно, должно быть признано в Соединенных Штатах Америки, статья фокусируется на различиях в методологических подходах к этому закону в странах с системами континентального и общего права.

В Конституции США нет конкретной статьи о неприкосновенности частной жизни, однако деятельность судов выявила конституционные основы защиты частных прав от произвольного вмешательства в некоторые конфиденциальные области частной жизни. Она основана на защите индивидуальных свобод от вмешательства государства, и это закреплено в четвертой, пятнадцатой и четырнадцатой поправках к Конституции.

Целью статьи является определение общей характеристики защиты персональных данных: анализ законодательства и прецедентного права.

Анализ исследований и публикаций. В доктрине и прецедентном праве обоснование необходимости нормативно-правового закрепления защиты персональных данных рассматривается в работах Н. Терри ${ }^{7}$, Л. Сотто 6 , С. Ходжес ${ }^{5}$, М.У. Бреннан ${ }^{2}$, Ф.С. Члаповски ${ }^{4}$ и др.

Изложение основного материала. В целом в Соединенных Штатах Америки существует отраслевой подход к конфиденциальности данных. Нет специального федерального закона, который гарантировал бы конфиденциальность и защиту персональных данных. Вместо этого законодательство на федеральном уровне в первую очередь защищает данные в определенных секторах. В отличие от Общего Регламента ЕС, в Соединенных Штатах Америки действуют федеральные законы и законы штатов, административные и

(C) А. Поладов, 2020

* Araz Poladov, Ph.D. Candidate of Baku State University 
отраслевые правила саморегулирования. Меры безопасности для защиты частной жизни зависят от конкретной области, и в этом отношении существует ряд законодательных актов и судебных прецедентов. Эти акты применяются только к конкретным областям, таким как «здравоохранение, образование, связь, защита прав детей и финансовые услуги, или случаи сбора данных в Интернете» 7 . Хотя на первый взгляд юристы-компаративисты имеют несколько негативное отношение к американской системе защиты конфиденциальности, именно американская система защиты персональных данных является более надежной и сложной, чем европейская.

В Соединенных Штатах Америки нет всеобъемлющего закона о защите персональных данных. В США законы о защите данных противоречивы. Они обычно применяются к государственным органам, а не частным. Есть некоторые законы, которые регулируют отдельные учреждения, но они очень специфичны, то есть они применяются только к определенной области. В дополнение к законам есть некоторые прецеденты, комментирующие конституционную защиту, которые также близки к определению права на защиту персональных данных ${ }^{1}$. На федеральном уровне наиболее важными законами являются Закон 1974 г. «О защите частной жизни» и Закон 2002 г. «Об обеспечении доступа граждан к государственной информации и услугам» (или «Закон о свободе информации»). Тем не менее, они относятся только к федеральным агентствам.

Закон о конфиденциальности 1974 г. устанавливает процедуры обработки персональных данных: процедуры сбора, хранения, использования и распространения персональных данных, хранящихся в базах данных федерального правительства. В то же время гражданам предоставляется возможность получить информацию о себе, хранящуюся в базах данных этих агентств, запрещается исправлять, добавлять или раскрывать эту информацию без письменного согласия лица. Закон 2002 г. устанавливает стандарты для государственных электронных ресурсов, связанных с оборотом персональных данных. Закон о свободе информации позволяет любому получить доступ к документам, хранящимся в федеральных агентствах, за некоторыми исключениями. Два исключения обеспечивают некоторую степень защиты данных. Во-первых, «кадровые и медицинские записи и открытые документы не допускаются к аналогичным документам, которые могут открыто и неоправданно ущемлять личную информацию». Во-вторых, «записи или информация, собранные для правоохранительных целей», не допускаются.

Защита персональных данных всегда была в центре внимания коммерческого и финансового сектора. Законодательство в этих областях постоянно совершенствуется. Первым и наиболее важным из этих законов является Закон 1970 г. «О справедливой кредитной отчетности». Этот закон широко регулирует сбор и раскрытие информации, защищенной кредитными организациями. Согласно закону, кредитные учреждения должны применять «разумные процедуры по обеспечению максимально возможной точности» информации, хранящейся в них, а также предоставлять всеобъемлющую процедуру раскрытия для желающих возразить против полноты или точности любой информации. Разглашение любого кредитного отчета другим физическим или юридическим лицам запрещено.

В целом, Федеральная торговая комиссия, независимый правоохранительный орган США, ставший в стране агентством по обеспечению конфиденциальности, играет важную роль в защите личной информации. Однако основные правовые функции Федеральной торговой комиссии вытекают из раздела 5 Закона «О Федеральной торговой комиссии». Юрисдикция Федеральной торговой комиссии заключается в выявлении и оспаривании нарушений конфиденциальности организациями, чья информационная практика считается «мошеннической» или «несправедливой»6. В этом смысле Федеральная торговая комиссия - это широкая система защиты потребителей, используемая для запрещения нечестных или вводящих в заблуждение действий, связанных с раскрытием и процедурами защиты личных данных.

Закон «О модернизации финансовых услуг» (или Закон Грэма-Лича-Блейли) защищает «непубличную» личную информацию потребителей при использовании финансовыми учреждениями. Согласно закону, «персональные данные» или «непубличные персональные данные» означают личную финансовую информацию, предоставленную потребителем финансовому учреждению; информацию, полученную в результате транзакции с потребителем или услуги, предоставленные потребителю, или информацию, полученную другим финансовым учреждением. Конфиденциальные личные данные защищены. Личная информация, открытая для общественности, не защищена. Сторонники закона настаивают на том, что политика регулирования персональных данных должна включать описание условий использования сервиса на понятном для пользователя языке, указывать, что пользовательские данные хранятся точно, кто их хранит и для какой цели. Критики утверждают, что эффективность защиты личных данных зависит от способности уклоняться от требований Закона, и для его повышения необходимо разработать методы информирования пользователя о правовых последствиях, а также всестороннее понимание того, как будут использоваться данные 5.

Закон 2003 г. «О нежелательных порнографиях и маркетинге», инициированный сенаторами Конрада Варенсом и Роном Уайденом, регулирует сбор и использование электронной почты. Закон распространяется на все сообщения электронной почты, основной целью которых является реклама или продвижение коммерческого продукта или услуги, а также на все коммерческие сообщения, определяемые как сообщения электронной почты, рекламирующие контент на коммерческих сайтах. Закон не исключает электронную почту между предприятиями, поскольку сообщения, отправленные бывшим клиентам с объявлением о новых продуктах, также должны соответствовать закону. Важно отметить, что данный Закон не создает права индивидуальных действий для потребителей. Напротив, основная ответственность за реализацию Закона лежит на Федеральной торговой комиссии. Многие федеральные и государственные органы, наряду с интернет-провайдерами, имеют возможность применять положения этого закона².

Закон 1986 г. «О конфиденциальности электронных данных» запрещает подслушивание личных данных других лиц без предварительного согласия одной из сторон и без разрешения суда. Запрещается исполь- 
зование или разглашение любой информации, полученной в результате незаконного прослушивания или электронного наблюдения.

Закон «О компьютерном мошенничестве и насилии» направлен на предотвращение и наказание за хакерскую деятельность, которую он определяет как «несанкционированный доступ» к защищенным компьютерам. Кроме того, Закон запрещает физическим или юридическим лицам покидать «разрешенное» место.

Наконец, судебная практика и судебные решения в разное время играли важную роль в регулировании правовых отношений в области защиты персональных данных в Соединенных Штатах.

Следует отметить, что до 1970-х гг. решения судов в США не обеспечивали необходимой защиты частной жизни. По делу Whalen v. Roe в 1977 г. Верховный Суд единогласно постановил, что регистрация конкретной централизованной базы данных в штате Нью-Йорк, содержащей имена и адреса лиц, прописывающих определенные лекарства, не нарушает права на неприкосновенность частной жизни. Верховный Суд постановил, что различные типы защищенных интересов конфиденциальности включают «предотвращение разглашения личных документов». Верховный Суд также отметил, что в различных ситуациях интересы государства имеют приоритет перед интересами личности ${ }^{8}$.

До конца XX в. информация о неприкосновенности частной жизни не обеспечивалась необходимой правовой защитой в судах США. Таким образом, Верховный Суд go делу Whalen v. Roe признал, что закон штата Нью-Йорк, согласно которому врачи и фармацевты должны сообщать государству о всех назначениях определенных лекарств и хранить их в полных базах данных, не нарушает права на неприкосновенность частной жизни, несмотря на протесты некоторых пациентов и врачей.

Некоторые эксперты даже называют решение Верховного Суда США вторжением в личную жизнь. Однако было много сторонников этого решения. Дело в том, что Верховный Суд поставил интересы государства выше интересов частной жизни людей при мониторинге информации о контроле над наркотиками. В то время в американском обществе существовало мнение, что хотя некоторые суды признают неприкосновенность личных данных, суды должны сбалансировать свои решения и, в любом случае, принимать их независимо, принимая во внимание общественные интересы ${ }^{4}$.

В своем решении от 18 июня 1981 г. по делу США против «Вестингауза» (US vs. Westinghouse), Aпелляционный Суд девятого округа разработал «тест баланса», который будет использоваться сторонами при принятии решения о конфликте интересов. При поиске такой информации необходимо учитывать следующие факторы: вред, который может быть нанесен пострадавшему лицу, а также меры по защите информации от любого раскрытия и вопросы, представляющие общественный интерес 9 .

В решении Верховного Суда 1967 г. Кац против США (Katz vs. US) подчеркивалось, что четвертая поправка к Конституции США запрещает прослушивание телефонных разговоров без официального ордера, при этом Верховный Суд постановил критерий «разумного ожидания конфиденциальности» ${ }^{3}$. Решение по делу Кац против Соединенных Штатов продемонстрировало значительные изменения в законодательстве США, поскольку Верховный Суд пересмотрел свою позицию в предыдущем решении по национальному делу 1928 г. Олмстед против Соединенных Штатов (Olmstead v. United States). Однако в решении указывалось, что четвертая и пятая поправки к Конституции США не имеют отношения к прослушиванию телефонных разговоров.

Эти суждения имеют ограниченную сферу действия и не оказывают существенного влияния на частный сектор, где возникает много вопросов о защите персональных данных.

Результаты исследования. Таким образом, развитие права на неприкосновенность частной жизни в Соединенных Штатах развивалось от признания доктринальных и судебных прецедентов до формирования и совершенствования системы конкретных правовых актов, которые всесторонне регулируют право на неприкосновенность частной жизни в различных областях человеческой деятельности. На ранних этапах формирования доктрины права на неприкосновенность частной жизни решения британских судов оказали серьезное влияние на этот процесс.

Важная роль в формировании права на неприкосновенность частной жизни в США также принадлежит континентальному праву (прежде всего французскому). Необходимо оценить и доктринальное влияние американского права на правовые концепции ЕС, поскольку Соединенные Штаты уже имели устоявшуюся судебную практику по этому вопросу, когда появилась Европейская конвенция о защите прав человека и основных свобод и первоначальные документы о защите личных данных.

В современном праве США право на частную жизнь определяется как «право быть оставленным в покое». Эта концепция охватывает ряд различных прав, которые защищают лица от вмешательства в личные отношения или деятельность, а также право каждого принимать независимые решения относительно своего жизненного выбора. Это право не является абсолютным. Право на частную жизнь может не защищать от некоторых социально опасных действий, таких как незаконное употребление наркотиков.

${ }^{1}$ Blanke M.J. "Safe Harbor" and The European Union's Directive on Data Protection. Safe Harbor Albany Law Journal. 2016. Vol. 11. № 4: 43. P. 101-134. P. 110 .

2 Brennan M.W. Complying with the CAN-SPAM Act. Lexis Practice Advisor Journal. 2016.

3 Carmen R. Criminal Procedure: Law and Practice. Belmont: Cengage Learning, 2007. 640 p. P. 324-325. P. 147.

${ }^{4}$ Chlapowski F.S. The Constitutional Protection of Information Privacy. Boston University Law Review, 1991. № 71. P. $133-160$.

5 Hodges, S. Examining the Gramm-Leach-Bliley Act's opt-out method for protecting consumer data privacy rights on the Internet. Information and communications technology law. Oxford, 2013. Vol. 22. № 1. P. 60-85. P. 85.

Часопис Київського університету права • 2020/2 


\section{Правова система України й міжнародне право, порівняльне правознавство}

${ }^{6}$ Sotto L.J., Simpson A.P. United States. Data Protection \& Privacy in 26 Jurisdictions Worldwide. 2014. 204 p. P. 191.

7 Terry, N. Existential Challenges for Health Care Data Protection in the United States // Third Ethics, Medicine, and Public Health. 2017. № 19-27. P. 21.

8 URL: https://caselaw.findlaw.com/us-supreme-court/429/589.html

${ }^{9}$ URL: https://www.globalhealthrights.org/health-topics/occupational-health/united-states-v-westinghouse/

\section{Резюме}

\section{Поладов А. Правила захисту персональних даних у правовій системі США.}

Мета: визначити загальну характеристику захисту персональних даних: аналіз законодавства й прецедентного права.

Методи: аналіз і вивчення нормативно-правових документів, що містять у собі положення про захист персональних даних.

Результати: визначено нормативну і практичну корисність закріплення положення про захист персональних даних у різних правових актах. Право на недоторканність приватного життя зміцнило свої позиції в Сполучених Штатах Америки наприкінці XIX в. і в цей час визнається більшістю штатів. Хоча право на недоторканність приватного життя в Сполучених Штатах Америки споконвічно було британською політичною спадщиною, судові рішення в Англії були більш консервативного й обережними, аніж рішення американських суддів. Однією з важливих особливостей цього права в англосаксонській правовій системі $€$ те, що воно раніше було сформовано судовими прецедентами й правовою доктриною. Слід зазначити, що право на недоторканність приватного життя не входило до числа суб'єктивних прав, передбачених у Біллі про права. У цілому в Сполучених Штатах існує галузевий підхід до конфіденційності даних. Не існує спеціального федерального закону, що гарантував би конфіденційність і захист персональних даних. Замість цього законодавство на федеральному рівні захищає передусім дані в певних секторах. Судова практика й судові рішення, прийняті в різний час, відіграють важливу роль у регулюванні правовий відносин в області захисту персональних даних у США. Слід зазначити, що до 1970-х рр. рішення судів США не забезпечували необхідного захисту приватного життя.

Обговорення: пропозиція всебічного й детального вивчення й використання цієї практики в інших державах.

Ключові слова: США, персональні дані, особисте життя, право на недоторканність приватного життя, прецедентное право, федеральне законодавство, секторальні закони, Федеральна торговельна комісія, свобода інформації.

\section{Резюме}

Поладов А. Правила защиты персональных данных в правовой системе США. права.

Цель: определить общую характеристику защиты персональных данных: анализ законодательства и прецедентного

Методы: анализ и изучение нормативно-правовых документов, содержащих в себе положения о защите персональных данных.

Результаты: определена нормативная и практическая полезность закрепления положении о защите персональных данных в различных правовых актах. Право на неприкосновенность частной жизни укрепило свои позиции в Соединенных Штатах Америки в конце XIX в. и в настоящее время признается большинством штатов. Хотя право на неприкосновенность частной жизни в Соединенных Штатах Америки изначально было британским политическим наследием, судебные решения в Англии были более консервативными и осторожными, чем решения американских судей. Одной из важных особенностей этого права в англосаксонской правовой системе является то, что оно ранее было сформировано судебными прецедентами и правовой доктриной. Следует отметить, что право на неприкосновенность частной жизни не входило в число субъективных прав, предусмотренных в Билле о правах. В целом в Соединенных Штатах существует отраслевой подход к конфиденциальности данных. Не существует специального федерального закона, который гарантировал бы конфиденциальность и защиту персональных данных. Вместо этого законодательство на федеральном уровне в первую очередь защищает данные в определенных секторах. Судебная практика и судебные решения, принятые в разное время, играют важную роль в регулировании правовых отношений в области защиты персональных данных в США. Следует отметить, что до 1970-х гг. решения судов США не обеспечивали необходимой защиты частной жизни.

Обсуждение: предложение всестороннего и детального изучения и использования этой практики в других государствах.

Ключевые слова: США, персональные данные, личная жизнь, право на неприкосновенность частной жизни, прецедентное право, федеральное законодательство, секторальные законы, Федеральная торговая комиссия, свобода информации.

\section{Summary}

Araz Poladov. Data protection rules in the united states legal system.

Purpose of research: define the general characteristics of the protection of personal data; analysis of legislation and case law.

Methods of research: analysis and study of regulatory documents containing provisions on protection of personal data.

Results: normative and practical importance of personal data protection provisions in various legal acts has been underscored. The right to privacy strengthened its position in the United States in the late 19th century and is now recognized by most States. Although the right to privacy in the United States was originally a British political legacy, judicial decisions in England were more conservative and cautious than those of U.S. courts. One of the important features of this law in the Anglo-Saxon legal system is that it was previously formed by judicial precedents and legal doctrine. Also, the right to privacy was not among the rights provided for in the Bill of Rights. In general, there is an industry-wide approach to data privacy in the United States. There is no specific federal law that would guarantee the confidentiality and protection of personal data. Instead, legislation at the federal level is dispersed and aims to protect data in certain sectors. Judicial practice and court decisions taken at different times play an important role in regulating personal data protection in the United States. It is also worth mentioning that until the 1970s, decisions of the U.S. courts did not provide the necessary privacy protection safeguards.

Discussion: offering a comprehensive and detailed study and use of this practice in other states.

Key words: United States, personal data, privacy, right to privacy, case law, federal legislation, sectoral laws, Federal Trade Commission, freedom of information. 